\title{
EL CUENTO MEDIEVAL: CRUCE DE CULTURAS
}

\author{
María Jesús LacARra \\ Universidad de Zaragoza \\ jlacarra@unizar.es
}

El cuento alcanzó una inusitada difusión en la Edad Media, pero sus especiales características -brevedad, tradicionalidad, didactismo, etc.,-- hicieron de él hasta hace unos años un género relegado por los estudiosos. La inconcreción de sus perfiles, así como la confluencia con otras formas breves, unido a su multiplicidad y heterogeneidad junto a, en muchas ocasiones, un pobre desarrollo narrativo implicó que su catalogación fuera postergada por la crítica moderna. Baste recordar cómo, para Paul Zumthor, las formas simples están tan entremezcladas en la tradición medieval que no hay ninguna pura, afirmación que le permite no adentrarse en el problema ${ }^{1}$. Ya en la expresión elegida, 'formas simples', reconocemos la herencia de la propuesta metodológica de André Jolles, cuyo pionero trabajo está detrás de las sucesivas aproximaciones teóricas hacia los relatos breves, aunque sea para transformar sus propuestas, como hizo Hans Robert Jauss ${ }^{2}$. En el cuento se acentúan todos los rasgos característicos de la literatura medieval y dificultan su estudio, como la ausencia de un canon, su vinculación a la oralidad, sus imprecisos límites cronológicos, la frecuente anonimia, la genérica y la confluencia de tradiciones.

Desde 1998 un grupo de investigadores, principalmente españoles y franceses, conscientes de estas dificultades, nos hemos ido reuniendo para abordar la tipología de las formas breves del ámbito románico ${ }^{3}$. Estos encuentros, de

${ }^{1}$ Paul Zumthor, Essai de poétique médiévale, Paris, Ed. du Seuil, 1972.

${ }^{2}$ André Jolles, Einfache Formen. Legende, Sage, Mythe, Spruch, Kasus, Memorabile, Märchen, Witz, Halle (Saale), 1930; trad. francesa, Paris, Ed. du Seuil, 1972; Hans Robert Jauss, Alterität und Modernität der mittelalterlichen Literatur, Munich, Wilhelm Fink, 1977.

${ }^{3}$ Tipología de las formas narrativas breves románicas medievales, ed. de Juan Paredes y Paloma 
carácter más general, se han alternado con otros, más restringidos temáticamente, centrados en la complejidad del cuento a partir de la asimilación y reelaboración de diversas tradiciones culturales ${ }^{4}$. En esa misma línea, este volumen monográfico, acogido con generosidad por Fernando Gómez Redondo en la Revista de poética medieval, se propone estudiar cómo el cuento es un campo perfecto para descubrir el cruce de culturas orientales y occidentales, románicas, célticas o germánicas, orales y escritas. Como señala Gaetano Lalomia en estas mismas páginas, «è un materiale assorbente che riesce a catturare storie da qualsiasi contenitore, per poi operare una profonda rielaborazione dei temi secondo le finalità con cui la voce narrante, scritta od orale che sia, intende raccontare la storia». Para su elaboración ha habido que ejercer una selección, puesto que son muchos los investigadores que en estos últimos años se han acercado al mundo del cuento oriental, el exemplum, el relato folclórico, etc. Por último, dada la confluencia de planteamientos de los trabajos aquí reunidos, y la interrelación de sus contenidos, no aparecen distribuidos con criterios temáticos, aunque puedan descubrirse con claridad las líneas que los unifican.

La literatura occidental asimiló en distintos momentos cuatro colecciones de cuentos, Calila e Dimna, Sendebar, Barlaam e Josafat y las Mil y una noches, cuyo origen remoto pudo estar en la India o Persia, pero que circulaban en el mundo árabe adaptadas a su entorno cultural. Una de las claves de su popularidad radica en su curiosa organización que no solo implica en muchos casos una estructura perfecta y muy cuidada, sino que supone una gran fe en el poder persuasivo del arte de contar, gracias al cual unos personajes logran salvar la vida. Algunos de sus procedimientos formales se reflejarán, a partir del siglo XIV, en las sucesivas colecciones que irán surgiendo en Occidente, desde El conde Lucanor hasta el Decamerón o los Cuentos de Canterbury, y en esa transmisión la Península Ibérica y Sicilia, como muestra Gaetano Lalomia, desempeñaron un papel fundamental. El Sendebar se tradujo por vez primera a una lengua romance en 1253 a partir de un original árabe perdido, por deseo de don Fadrique (1224-1277), hijo de Fernando III, siguiendo así

Gracia, Universidad de Granada, 1998, Typologie des formes narratives brèves au Moyen Âge (domaine roman), ed. de Bernard Darbord, Crisol, Nouvelles série, $2^{\circ} 4$ (2000), Tipología de las formas narrativas breves románicas medievales, ed. de Juan Manuel Cacho Blecua y M. ${ }^{a}$ Jesús Lacarra, Universidad de Zaragoza-Universidad de Granada, 2003, Formas narrativas breves en la Edad Media, ed. de Elvira Fidalgo, Universidad de Santiago de Compostela, 2005, Typologie des formes narratives brèves au Moyen Âge, ed. de Bernard Darbord, Paris, Presses Universitaires de Paris Ouest, 2010 y Formas narrativas breves. Lecturas e interpretaciones, ed. de Carlos Alvar, San Millán de la Cogolla, Cilengua, 2014.

${ }^{4}$ El cuento oriental en España, ed. de María Jesús Lacarra y Juan Paredes, Granada, Fundación Euroárabe, 2006; Incontro di culture. La narrativa breve nella Romània medievale, ed. de Rosanna Brusegan y María Jesús Lacarra, monografía de Medioevo romanzo, 30.11 (2006). 
la huella de su ilustre hermano, el rey Alfonso X. En su extenso recorrido de Oriente a Occidente la colección fue sufriendo cambios y adaptaciones con nuevas versiones occidentales, algunas de las cuales serán 'retraducidas' al castellano a lo largo de los siglos XV y XVI, dando paso a nuevos testimonios como la Novella de Cañizares, los Siete sabios de Roma o el Erasto de Pedro Hurtado de la Vera. El estudio global de todas estas versiones permitiría conocer la capacidad de transformación de la colección para ajustarse a los cambiantes gustos literarios de recepción, pero parecidas conclusiones pueden obtenerse del análisis de un solo relato. La propuesta de Marta Haro consiste en detenerse en Balneator o Senescalus, uno de los cuentos más interesantes y que menos atención ha despertado en la crítica, para observar la permanente adaptación de la historia a nuevos contextos. La anécdota se mantiene inalterable en todas las versiones orientales, pero en el Libro de los Siete sabios se fusionan de modo impecable dos relatos, Senescalus y Roma, en lo que parece un reflejo de la campaña que mueve Carlos VIII entre 1494 y 1495 para apoderarse de Nápoles, saqueando Roma previamente, defendida a duras penas por Alejandro VI.

Junto a la tradición oriental, la Península no se quedó al margen de los cambios surgidos en la Iglesia tras el IV Concilio de Letrán. A partir del siglo XIII el modelo de predicación basado en el comentario verso a verso del Evangelio comienza a ser considerado antiguo, y solo adecuado para los iletrados. Con la aparición de nuevas órdenes religiosas, se fue sistematizando el método homilético, haciéndose más culto, pero sin perder nunca su dimensión popular. Según nos revelan las artes praedicandi, el sermón se organiza en torno a una cita, el thema, generalmente extraída de la Biblia. Sigue habitualmente la localización del pasaje para que se compruebe su coincidencia con alguna de las lecturas de la liturgia del día. Para su mayor comprensión, el discurso se subdivide y cada una de las subdivisiones se somete a un proceso de amplificación, la dilatatio. Los recursos son muy variados, aunque las citas de autoridades, los símiles y los exempla son los principales. Estos últimos son el medio adecuado para captar la atención de unos oyentes, mayoritariamente analfabetos y poco habituados a la sutilezas teológicas. De ello se dieron pronto cuenta los cistercienses, pero en seguida las órdenes mendicantes, franciscanos y dominicos, impulsarán su utilización y recopilación en ejemplarios. De este modo la Iglesia se convierte en la principal fuerza difusora de cuentos, a los que, mediante la moralización adecuada, busca una utilidad pedagógica.

Con nuestros datos actuales no parece que entre los recopiladores de ejemplarios haya destacado ningún español, lo que no impide que contemos 
con una rica tradición de ejemplos en lengua vulgar que se va incrementando con nuevos hallazgos, como sucede con el códice 48 de la biblioteca de la catedral de Pamplona, en el que se recogen varios materiales útiles para la preparación de sermones, entre ellos una colección de siete exempla escritos en dialecto navarro. Se trata de historias bien conocidas, pero contadas con profusión de detalles y de manera muy desarrollada. En algunos casos coinciden con exempla de las Vitae fratrum de Gérard Frachet, las Cantigas de Santa María o el Libro de los exemplos por $A B C$, pero también puede reconocerse una versión simplificada de la leyenda de Roberto el Diablo. El corpus ejemplar, aquí estudiado y editado por Beatriz Marcotegui, refleja una serie de temas muy propios de la espiritualidad bajomedieval, tales como la necesidad del sacramento de la confesión y de hacer penitencia para alcanzar la salvación eterna, o la consideración de la Virgen María como mediadora e intercesora de los pecadores ante Dios.

Las bibliotecas españolas guardan copias de los ejemplarios latinos más importantes, algunos de los cuales fueron romanceados a finales de la Edad Media. El proceso, indicio del acceso de seglares al género, se produce posiblemente a finales del siglo XIV, momento al que podemos adscribir la versión castellano-leonesa de las Fábulas o Narraciones de Chériton, conocida con el enigmático título de Libro de los gatos. El texto español contiene 64 ejemplos, de los que solo dos (la segunda parte del 28 y el 43) carecen de correspondencia con el texto latino. El ejemplo 28 se constituye a partir de dos anécdotas («Los monos recompensan a un mentiroso» y «La curación del rey y de la princesa»). La primera, procedente de Odo de Chériton, coincide con otros ejemplarios, pero la segunda, ajena al modelo latino, se corresponde con uno de los cuentos folclóricos más extendidos. Como estudia Bernard Darbord se trata de una variación, al igual que tres ejemplos de $\mathrm{El}$ conde $\mathrm{Lu}$ canor (26, 43 y 48), del cuento de «Los dos compañeros». El éxito del tipo folclórico AT 613 en la tradición universal es un reflejo del destino humano como homo viator, siempre vacilando, en busca del buen camino.

La dependencia, mayor o menor, de los ejemplarios hispánicos en relación a sus modelos latinos se quiebra en el caso de Ramón Llull, cuyo originalidad se entiende también como resultado de la recreación de tradiciones literarias orientales y occidentales. José Aragüés se detiene en el Arbre exemplifical, que ofrece numerosas claves a propósito de la evolución del exemplum luliano. En el texto confluyen algunas formas ya ensayadas por el autor (ejemplos verosímiles, fábulas) con otras narraciones de aspecto mucho más original, protagonizadas por personificaciones de todos los entes, materiales o espirituales («ejemplos artísticos»). El Arbre exemplifical desborda así su intención 
inicial (la iluminación del Arbre de ciència), para erigirse en un repertorio de formas preparadas para su inserción en cualquier discurso. Esas formas, además, se ofrecen como modelos para la creación de nuevas secuencias, confirmando el carácter experimental e inacabado que ostenta tantas veces la literatura ejemplar del Beato.

En torno a la primera mitad del siglo XIV el cuento hispánico empieza a adquirir su desarrollo artístico, despegándose de los modelos orientales u occidentales más próximos. Don Juan Manuel, el autor del Zifar o Juan Ruiz alcanzan en muchos momentos cotas magistrales en el 'arte de contar', pero esto no hay que entenderlo como 'originalidad' de sus argumentos. La literatura ejemplar, el cuento oriental y la tradición oral les ofrecen unos materiales, muchas veces coincidentes, y con ellos elaboran sus creaciones, que reajustan para adecuarlas a nuevos contextos narrativos. El Libro del caballero Zifar sorprende por la variedad de sus modelos, continuado cruce entre Oriente y Occidente, como se percibe tanto en el análisis de sus unidades breves, como en el de algunos episodios. La influencia oriental habría que vincularla con su probable origen toledano, que ha llevado incluso a algunos críticos a presuponerle un modelo árabe, sin que la hipótesis haya prosperado. Esta huella no solo se percibe en la trama principal, sino en gran parte de los numerosos cuentos insertados, con los que los personajes, en especial el protagonista, aleccionan a sus receptores, o en los episodios sobrenaturales, a medio camino entre las maravillas artúricas y el mundo de las Mil y una noches. En relación con estos últimos, David A. Wacks propone releer las aventuras del Caballero del Lago y el episodio de Roboán y Nobleza a la luz del Ziyād ibn 'Ämir, al-Kinānī, obra de contenido caballeresco de dimensiones reducidas y plagada de elementos maravillosos que ya fue traducida en 1882 por Francisco Fernández y González, con el título de Libro del Alhadis o Libro de la Historia de Zeyyad Ben-Amir. Las quejas de Menéndez Pelayo porque se publicara en el Museo Español de Antigüedades, que al parecer nadie leía, posiblemente porque eran volúmenes pesados y difíciles de manejar, parecen premonitorias, ya que los pocos estudiosos que hasta ahora lo han citado se han limitado a reproducir estos mismos datos. El pormenorizado análisis de Wacks prueba cómo el autor del Zifar retoma y adapta motivos de esta peculiar obra de la literatura popular andalusí.

Los cuentos insertados en el Zifar sorprenden también por la independencia que muestran respecto a sus posibles modelos; así la fábula de «El lobo y las sanguijuelas», estudiada por Luzdivina Cuesta, no aparece en la tradición esópica medieval, aunque puede reconocerse el precedente en la Retórica aristotélica (II, 20), hasta tal punto transformada que casi puede hablarse de 
una fábula nueva y original. Es posible, sin embargo, que el autor la haya conocido de forma indirecta, a través de uno de los manuscritos del conjunto llamado Aristóteles latino, o que no dispusiera de la fuente en el momento de la escritura, o, incluso, que circulara de forma oral. Pero más allá de los hipotéticos modelos, la originalidad del autor es evidente y, casi con seguridad, voluntaria, fruto de un propósito artístico. Las modificaciones que realiza se encaminan a adaptar mejor la fábula al contexto en que va a ser aplicada, y a perfeccionar el relato, ampliándolo hasta duplicar su tamaño original y dotándolo de múltiples detalles que lo convierten en un cuento verosímil.

El conde Lucanor se construye de acuerdo con unos mecanismos didácticos, recreados por don Juan Manuel a partir de modelos orientales y occidentales. Como recuerda Juan Paredes, el autor, cuya presencia es constante y de una manera casi obsesiva en toda la obra a través de sus personajes, aparece de manera explícita al final de cada ejemplo para concretar su significado y resumirlo, de modo mnemotécnico, en los versos. Por último las perdidas ilustraciones ayudarían a preservar en la memoria la enseñanza. La distancia que va de la tradición ejemplar al Libro de los exemplos manuelino viene marcada por esta preocupación artística y doctrinal capaz de vivificar una estructura en la que el autor se identifica con el conde Lucanor y este con sus personajes, para al final ser identificado por los propios lectores, que también asumen la enseñanza de los cuentos.

Estos proceden en gran medida de la literatura ejemplar dominica, sin olvidar la tradición oriental que le proporcionó múltiples materiales narrativos y sentenciosos, pero la obra podría ser también un buen espacio para debatir acerca de las relaciones entre tradición oral y escrita en la literatura medieval. Sin embargo, los numerosos estudios acumulados en estos últimos años inclinan notablemente la balanza hacia la búsqueda de fuentes escritas, sin que en la nutrida bibliografía juanmanuelina abunden los trabajos que aborden las huellas de la oralidad. El ejemplo 51, pese a hallarse en el margen y ser de discutida autoría, es un buen referente para descubrir estas confluencias. La historia del monarca soberbio cuenta con paralelos, hasta ahora desatendidos por la crítica, como recuerda José M. Pedrosa, que remontan al siglo xIII y tienen su continuidad en las numerosas adaptaciones castellanas de la llamada Summa de san Antonio, Arzobispo de Milán, escrita en latín y atribuida a tal arzobispo, quien vivió entre 1389 y 1459. Pero el relato se corresponde a su vez con el tipo folclórico ATU 757 y mantiene curiosas analogías narrativas con la épica así como con otras leyendas y cuentos tradicionales. Sus semejanzas tienen relación con el tratamiento que todas estas obras hacen de los pecados de la soberbia, de la ira y de la negación de la hospitalidad. 
Es bien sabido que don Juan Manuel sometía sus fuentes, bien fueran escritas u orales, a un proceso de enmascaramiento, encubriendo sus modelos, aunque pocos ejemplos muestran este procedimiento con tanta claridad como el 48. En él realiza una compleja síntesis del cuento de «El medio amigo» con el que se abre la Disciplina clericalis, a partir de las variaciones que esa misma historia experimenta en la tradición hispánica, como se refleja en los Castigos de Sancho IV, combinado con ingredientes de otros relatos vinculados al complejo de la amistad, como «El amigo íntegro», segunda historia de la Disciplina, o «Los tres amigos», procedente del Barlaam y Josafat. Se trata de un riquísimo "collage intertextual», en expresión de Salvatore Luongo, que ha llamado la atención de numerosos críticos sin que sea fácil descubrir sus claves.

En la segunda mitad del siglo XIV una figura como el canciller Ayala ilustra bien el cambio de orientación. La huella oriental deja paso ahora a la influencia de la cultura literaria francesa sin perder de vista la tradición hispánica. Tanto como embajador ante la corte papal de Aviñón como en sus reiterados viajes a Francia, Pero López de Ayala conocería a los escritores más destacados de la época y pudo también establecer relación con Jean de Berry, el gran duque bibliófilo, hermano del rey. En esta línea, Hugo Oscar Bizzarri propone estudiar las coplas 191 a 728 del Rimado de palacio a la luz del género de los État du monde. Esta crítica a los estados, que posee una elaborada estructura, va acompañada de numerosos exempla, que son un fiel reflejo de la realidad política y social de Castilla y de Europa. Responden siempre a un mismo tipo: el exemplum dramatizado, lo que entre los predicadores se llamaba 'Plática'. Están trabajados como si fueran cuadros de costumbres y la mayoría carecen de modelos directos, aunque algunos, como «Los mercaderes», «El bachiller en leyes y decretales» $\mathrm{o}$ «El malfechor», se corresponden más con la tradición de los états du monde. El Canciller se sirve de ellos para explicar la crisis que vive el Papado, retratar la avidez de los reyes y de los mercaderes, la situación de la justicia o los abusos de los arrendadores.

Con frecuencia se olvida que en la difusión de la cuentística oriental por Occidente tanta importancia tuvieron los árabes como los hebreos y, sobre todo, los conversos. Estos se convirtieron en el auténtico eslabón que permitió tender un puente entre Oriente y Occidente al contribuir, gracias a sus versiones latinas, a hacer accesibles los textos. Podríamos recordar la figura de Pedro Alfonso (Moisé Sefardí), cuya Disciplina clericalis facilitó en gran medida el trasvase de cuentos orientales hacia los ejemplarios, o la anónima versión hebrea del Sendebar, Mislé Sendebar, que sorprende por su especial proximidad con la traducción castellana medieval y que para algunos críticos 
sería el agente transmisor de esta colección hasta Occidente. En el siglo XIII se realizaron dos versiones hebreas del Calila y Dimna, ambas probablemente en Castilla, y gracias a un converso, Juan de Capua que tradujo una de ellas al latín, la obra alcanzó gran difusión por Occidente, llegando a influir en los novellieri, como recuerda Lalomia. Sin dejar a un lado la adaptación hebrea del Barlaam y Josafat, realizada en la primera mitad del siglo XIII por el judío barcelonés Ibn Hasday. Este rápido repaso, necesitado todavía de un detenido estudio, debería completarse con el recuerdo del género de la maqama hispanohebrea, desde El libro de los entretenimientos de Yosef Ibn Zabarra hasta el menos conocido Meshal haqadmoni, escrito a finales del siglo XIII por Isaac ben Solomon ibn Sahula, cuya vida transcurrió entre Burgos y Guadalajara. El estudio de esta última obra ha permitido descubrir interesante paralelos del ejemplo XI de El conde Lucanor o de «El cuento de los astrólogos y el hijo del rey Alcaraz» del Libro de buen amor. Con la incorporación de judíos conversos a las filas del cristianismo una gran parte del material narrativo que, con fines didácticos y religiosos, se hallaba disperso en la Haggadá rabínica, fue utilizado por estos nuevos cristianos para argumentar contra el judaísmo a partir de su propia tradición literaria y doctrinal. Amparo Alba y Carlos Sainz siguen el rastro de uno de los relatos más utilizados en las discusiones sobre el Mesías, el «Cuento del buey que bramó», que aparece en lengua romance en el curso de las controversias públicas, como la de Tortosa, y en los tratados de polemistas como el Pugio fidei del dominico y hebraísta Raimundo Martí.

No resulta extraño que la cuentística medieval, al igual que el romancero, las leyendas o los refranes, haya sobrevivido hasta nuestros días gracias a la cultura sefardí. El cuento folclórico sefardí, como estudia María Sánchez Pérez, es un auténtico cajón de sastre donde se suma el bagaje cultural que los judíos habían asimilado en su convivencia con musulmanes y cristianos junto a materiales de muy diversas tradiciones culturales. Con independencia de cuál sea en última instancia su procedencia, en las konsejas o konsejikas es posible todavía 'oír' cuentos que se conocían en la Península Ibérica en la Edad Media, como el «Ejemplo del ermitaño bebedor», que también puede leerse en el Libro de Apolonio o en el Libro de buen amor, «Los tres depositarios asociados», incluido en el Libro de los engaños, o el ejemplo $10 \mathrm{de} E l$ conde Lucanor («De lo que contesçió a un omne que por pobreza e mengua de otra vianda comía atramuzes»). En resumen, bajo diversos enfoques, metodologías y puntos de vista los artículos aquí reunidos pretenden mostrar cómo la originalidad del cuento medieval hispánico es el resultado de un enriquecedor cruce de culturas. 